\title{
The Metrical Structure of the Sapphic Hendecasyllable and Sappho's Aiolikon in Lesbian Poetry
}

\section{Anni Arukask}

\begin{abstract}
The works of Sappho and Alcaeus, $7^{\text {th }}-6^{\text {th }}$ century BC lyric poets from the island of Lesbos, represent the Aeolic tradition of ancient Greek poetry. In this paper, two metrical structures of this tradition, that both have two quantity-free positions (anceps, brevis in longo), are analysed and compared with regard to the quantitative tendencies of these positions. The first metrical structure, the Sapphic hendecasyllable, was used by both poets; the other, aiolikon, is not attested in Alcaeus's work. The analysed corpus consists of all the survived lines in these meters. Due to the fragmentary nature of the material, the statistical analysis is presented in two sets to add and include the data of the Sapphic and Alcaic lines about which there is a suspicion that they may be in these meters, and also to differentiate dubious data from the undubious. In addition, the statistical data of the quantitative tendencies of the undubious lines is also expressed with generative models. In general, all the free positions, except the ancipites of Sappho's aiolikon, display a preference for heavy syllables and the preference is more pronounced in the brevis in longo position, especially when it comes to aiolikon. Comparing the hendecasyllables, Alcaeus tends to have more heavy syllables than Sappho. Aiolikon's free positions exhibit the biggest quantitative contrast.
\end{abstract}

Keywords: Sapphic hendecasyllable, aiolikon, anceps, brevis in longo, comparativestatistical method, generative models, meter, lyric poetry, Sappho, Alcaeus, ancient Greek poetry

\section{Introduction}

The aim of the paper is, firstly, to present and compare the quantitative tendencies in the anceps and brevis in longo positions of two metrical structures in the poetry of Sappho and Alcaeus, two Lesbian singers of the $7-6^{\text {th }}$ century BC, and, secondly, to demonstrate, on the basis of these new data, the generative

\footnotetext{
* Author's address: Anni Arukask, University of Tartu, Lossi 3, 51003, Tartu, Estonia; email: anni.arukask@gmail.com.
} 
models of these verse forms. The two verse forms in question are the Sapphic hendecasyllable and Sappho's aiolikon. ${ }^{1}$

In Sappho's corpus, the whole Alexandrian first book (frr. 1-42 V) is in the Sapphic stanza (of which the hendecasyllable forms a part), and fragments in aiolikon are placed into the fourth volume (frr. 58-91 V), which is the first non-monometrical book (cf. Page 1955: 114-115; Lidov 2009: 107; Liberman 2007: 49). There might be a few lines in the Sapphic stanza among fragments without a book classification ${ }^{2}$ (cf. Voigt 1971: 15). As these two are the most prevalent metrical forms in her preserved corpus, they were chosen for the analysis.

Alcaeus has 11-22 fragments in Sapphic stanzas (cf. Voigt 1971: 21), while in Sappho's case, at least 40 such fragments have survived. In aiolikon, we have 4-12 Sapphic fragments. As there is no firm evidence that Alcaeus ever used that meter (cf. Lidov 2009: 105), only Sapphic lines are included in this number. The full numbers of the fragments in question are presented in such an indefinite manner because the meter of only some of them can be determined with certainty.

Alcaeus's corpus consists of about 400 fragments. Among its 11-22 Sapphic fragments, 10 certainly (61 lines) and 7 probably (22 lines) Sapphic fragments with hendecasyllables could be analysed. In the same vein, Sappho's corpus has 34 analysable fragments of Sapphic stanza with 384 certainly (from 33 fragments) and 11 probably (from 8 fragments) hendecasyllabic lines. In regard to aiolikon, there are 4 certain (32 lines) and 7 probable (26 lines) fragments.

The following charts depict the occurrence of the Sapphic stanza and aiolikon in Sappho's preserved corpus (frr. 1-168C Voigt, 1384 lines from 176 fragments).

Chart 1 shows that about $42 \%$ of the lines in the corpus cannot be analysed metrically when only the lines for which the metrical value can be determined with certainty are considered. The Sapphic stanza covers about $38 \%$ of the corpus and aiolikon $3 \%$. All other meters amount roughly to $18 \%$.

Chart 2 adds the lines for which a probable meter can be assigned.

Under these conditions, the Sapphic stanza and aiolikon cover about 38\% and $8 \%$ of the corpus respectively, other meters take $24 \%$ and about $30 \%$ is left undetermined.

1 The meter was called aiolikon by the 2nd-century AD Alexandrian philologist Hephaestion, referring to the fact that it was used by an Aeolic poet Sappho, whom he names as its frequent user. He classified it as an ionic and describes it as an acatalectic double tetrameter (to be more exact, three ionics with a trochee at the end). (Hephaestion Enchiridion de Metris 11.5)

2 Unclassified fragments begin from fr. 118 on. 


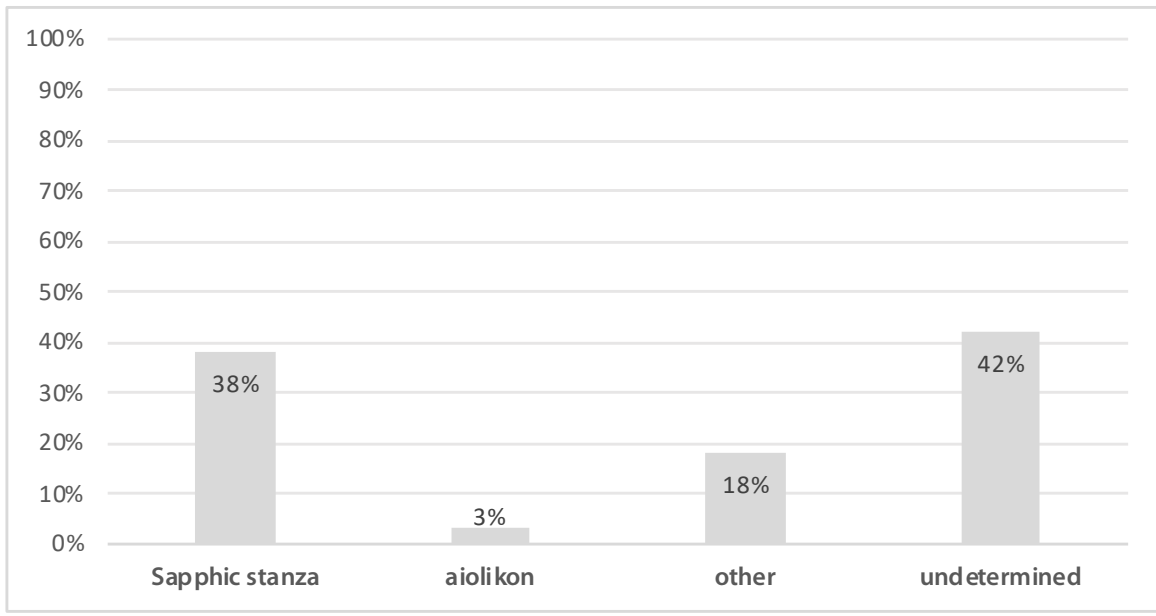

Chart 1. Metrical distribution of the lines in Sappho's preserved corpus between the Sapphic stanza, aiolikon, everything else, and undetermined meter when only lines with a surely determined metrical value are taken into account.

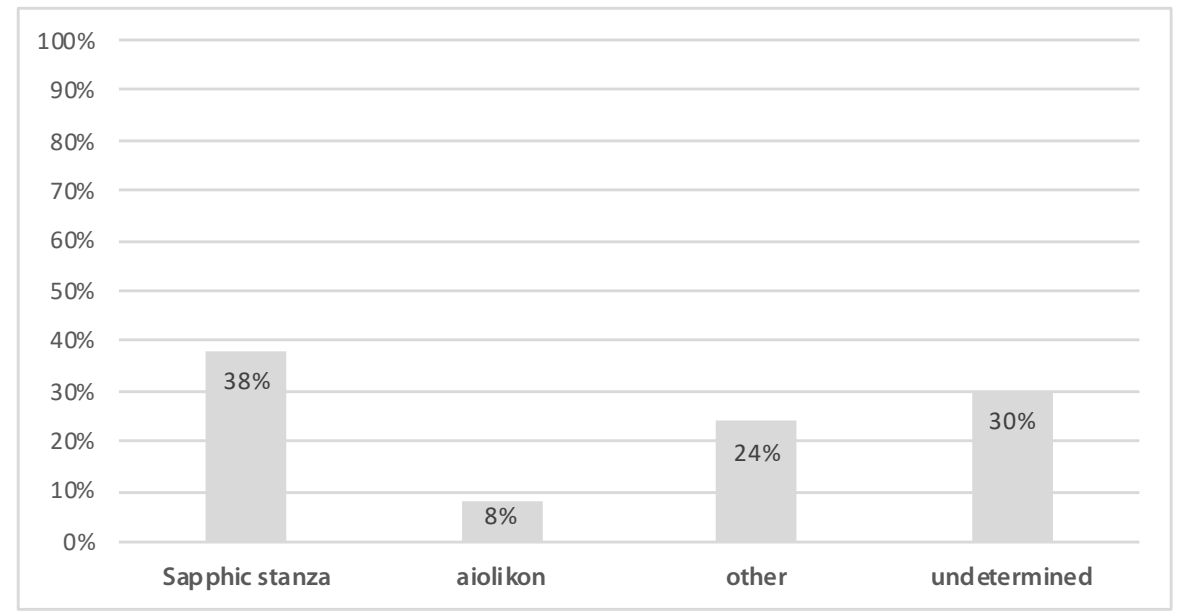

Chart 2. Metrical distribution of the lines in Sappho's preserved corpus between the Sapphic stanza, aiolikon, everything else, and undetermined meter when both the lines with a surely determined metrical value and lines with a probable metrical value are taken into account. 
Both these metrical structures are examples of the archaic nature of the Aeolic poetic tradition which - among Ancient Greek poetic traditions - is the closest to the reconstructed Indo-European verse in which quantities are regulated only towards the end of the verse and are free towards the beginning (vd. Meillet 1923). Aeolic metrical structures have a fixed number of syllables in a period (no contractions or resolutions), they are for the most part easily divided into cola, and often the first two positions are free in respect to quantity, although their realisation as two light syllables is rare (the Aeolic base). As the rhythm in the Aeolic base is thusly limited, West prefers to mark it with symbols $\circ \circ$, not $\times \times$. The cola are asymmetric and cannot be divided into feet $^{3}$ (West 1982: 29-30; 1987: 32-33).

Different authors have used different cola as the basis of their descriptions of Aeolic forms. Among Dietmar Korzeniewski's three base cola, the one most fitting for these two meters is the hipponactean (hi) ${ }^{4}$ (Korzeniewski 1968: 129). At the same time, for Martin West, the iamb is very important in relation to forming new cola by means of extension. ${ }^{5}$ There also exists a way of forming new cola by means of expansion ${ }^{6}$ (West 1982: 31-32).

The first of these Lesbian metrical structures, the Sapphic hendecasyllable, which was used by both poets, can be described as an acephalic hipponactean (" $\wedge$ " in the abbreviated colon name stands for acephalia) that has been extended with a cretic (cr) in the beginning (Korzeniewski 1968: 129); or, in West's terminology, a hagesichorean ${ }^{7}$ that is prefixed with an acatalectic iamb (West 1982: 32). The fourth position of the line is anceps, ${ }^{8}$ and the last position is brevis in longo. ${ }^{9}$

3 However, Marc Dominicy has made a solid attempt to reconstruct the composition and metrical structure of a large number of Aeolic lines with his new metrical grammar in which the cola are analysed into feet (vd. Dominicy 1994).

$4 \times \times-\cup \cup-\cup-\overline{-}$

5 Forming a new colon by means of extension means that another colon (some variant of an iamb) is suffixed or prefixed at a colon's borders.

6 Forming a new colon by means of expansion means that a colon is amplified by the repetition of another, smaller colon (usually a dactyl or choriamb) one to three times in the middle of that colon.

$7 \quad x-u \cup-u-v$

8 Anceps is a metrical position with unregulated quantity which therefore can be realised as either light or heavy (West 1982: 18; 1987: 5). It is never placed beside another anceps, with the exception of the Aeolic base and anaclasis (Maas 1962: 29).

9 The last position of a line is always free and unregulated (either heavy or light, an anceps), 


$$
[-\cup-] \times-\smile \cup-\smile-\Xi \quad \text { cr } \wedge \text { hi or } \wedge \text { ia ha }
$$

For the Lesbians, however, the hendecasyllable is never an independent meter, as it always appears as a part of the Sapphic stanza. The Sapphic stanza is a realisation of a quite common ${ }^{10}$ aaA verse-form; i.e., the last line is an amplification of the pattern present in the preceding lines (West 1982: 32-33):

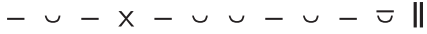

$$
\begin{aligned}
& -u-x-v v-v-\Xi \| \\
& -\smile-x-\cup \cup-\cup \vdots-x \vdots[-\cup \cup-\nabla]|l|
\end{aligned}
$$

In the third line, the hendecasyllable has been amplified with an adonic $(-\smile \smile--)$. The stanza is composed of periods that all have feminine or pendant endings. Lesbian authors hardly ever combine lines with endings of a different nature; i.e. all endings tend to be either masculine or feminine (Lidov 2009: 106).

Ancient colometry and also many modern editions tend to treat the last line as consisting of an 11-syllable and 5-syllable adonic part that separates into two lines after the 11th position, where caesura is frequent (West 1982: 33). This has resulted in the verse being perceived as a 4-line stanza by the ancient Romans and as well as other European traditions (cf. West 1982: 33), but in the 19th century, theoreticians started to argue that aaA strophe types should not be analysed and divided in that way. ${ }^{11}$

The other metrical structure, the aiolikon, which to our knowledge was never used by Alcaeus, is usually described as an acephalic hipponactean with a double choriambic (c) expansion (Lidov 2009: 104, 105; Ferrari 2010: 19, 118). The first position (anceps) and the last position (brevis in longo) of the line are free of fixed quantity.

but some rhythmic patterns create an expectation for a heavy syllable. When that position actually realises as light, that syllable is brevis in longo or syllaba brevis in elemento longo. The additional time would be filled with a following pause (cf. Quintilianus 9.4.93) (West 1982: 4-5; 1987: 4). For simplicity's sake, the line-final position will always be called brevis in longo in this article.

10 The verse form might be considered common just because many Sapphic and Alcaic stanzas have been preserved.

11 The first to raise the question were the German classical philologists Gottfried Hermann (1816: 687) and Heinrich Ludolf Ahrens (1868: 581). The first to comment specifically on the Sapphic and Alcaic stanzas was Otto Crusius (1888). 
$x-\cup \cup-[-\cup \cup--\cup \cup-] \cup-\bar{\wedge} \quad \mathrm{hi}^{2 \mathrm{c}}$

In addition, aiolikon is a stichic form - i.e., one that is used invariably in all lines throughout a poem - that is often marked down in dyads (cf. P. Oxy. 1787 frr. 3, 5, 34).

On the other hand, Chris Golston and Thomas Riad, who applied the fresher, language-based methods of generative metrics on Greek lyric poetry, find that it serves better to express lyric meters with simpler basic units than through cumbersome cola. ${ }^{12}$ According to their approach, the basic units are dactylic and trochaic, which are respectively marked by violations of linguistic constraints NoClash and NoLapse, ${ }^{13}$ as these constraints are ranked low in Greek phonology. In their scheme for the Sapphic hendecasyllable, "T" stands for a trochee and "D” for a dactyl (Golston, Riad 2005: 105, 77).

TDT

The aiolikon would probably be expressed as follows:

$\sigma \mathrm{T}_{\mathrm{an}} \mathrm{T}_{\mathrm{an}} \mathrm{DT}$

In the scheme, " $\sigma$ " symbolises an extrametical position and " $\mathrm{T}_{\mathrm{an}}$ " stands for an anaclastic trochee. However, Golston and Riad claim that choriambs, expressed here through $\mathrm{T}_{\text {an }}$, are typologically bizarre and problematic. They have analysed the cola with choriambic sequences as ones with dactylic cores (vd. Golston, Riad 2005: 110).

12 The multitude of analytic primes is said to result in less explanatory power of the system, many parallel acceptable ways to express the meters that can make the verse forms look unnecessarily complicated, and, additionally, the cola can only be used to analyse lyric poets ( vd. Golston, Riad 2005: 111-113).

13 NoClash is defined as 'Prominent syllables are not adjacent' and NoLapse as 'Unprominent moras/syllables must not be adjacent'. Also, trochaic and iambic are regarded as the same type of basic unit, both violating NoLapse. Other analytically necessary constraints that are less often violated are Exhaustativity (resulting in extrametricality), Binarity (resulting in catalexis) and Alignment (resulting in anaclasis). Exahustativity is defined as 'Every foot is directly dominated by a prosodic word' (vd. Golston, Riad 2005: 97, 101; 113; 104). 


\section{Methods}

As it would be intuitively expected that a particular quantity tends to dominate in the ambivalent positions of anceps and brevis in longo, the quantitative tendencies of the aiolikon and the Sapphic hendecasyllable were analysed in this regard using the comparative-statistical method.

For the Sapphic hendecasyllable, the analysis included and did not differentiate the so-called third lines of the Sapphic stanza and the pure hendecasyllabic ones $^{14}$ to make the data comparable with those of the subsequent users of this meter. In the case of Sappho's poetry, the sample consisted of 170 anceps positions and 151 brevis in longo positions from the lines in fragments that Voigt identifies as Sapphic stanzas and also from newer fragmentary finds associated with Dirk Obbink. ${ }^{15}$ When the whole fragment was preserved well enough to provide sufficient semantical context, the editors' guesses were trusted, taken into consideration and analysed. An alternative sample had 8 anceps and 3 brevis in longo positions added (the full sample sizes were therefore $178 \& 154$ ) that could not be determined with certainty or were from fragments that Voigt only suspects to be in the meter. The fragments for which Voigt offers an alternative meter were not included.

Voigt's Alcaic hendecasyllabic corpus was analysed with the same guidelines, and the sample consisted of 56 anceps and 21 brevis in longo positions. The alternative Alcaic sample with dubious positions added consisted of 15 and 10 more positions ( $71 \& 31$ ).

The same principles were also applied to Sappho's aiolikon, where the samples consisted of 21 anceps and 27 brevis in longo positions, and additionally, 31 anceps and 12 brevis in longo positions ( 52 \& 39). Fragment 59 was placed into the latter sample because - although it was preserved on the same supposedly monometrical papyrus as the older find of aiolikon fragment 58 (cf. Boedeker 2009: 71-72) - its few syllables do not give enough grounds to be sure that it is in aiolikon.

For quantitative analysis, a syllable filling the positions in question was considered heavy if it included a diphthong, long vowel (by nature) or closing consonant(s) (incl. muta cum liquida) (by position). All open syllables with a short vowel were considered light (cf. Smyth 1920: 35-36; Maas 1962: 75-76). In addition, it should be noted that in the Ancient Greek language, word borders

14 However, Joan Silva Barris has analysed the quantities of the 11th syllables of the lines of the Sapphic stanza. According to his results, the percentage of light syllables is $35-36 \%$ in the third line, while in the initial lines, it is nearly $40 \%$ (Barris 2011: 122).

15 Vd. Burris, Fish, Obbink 2014; Obbink 2009, and Obbink 2014. 
are not necessarily syllable borders, and there is no prosodic continuity between periods. Therefore, the quantity of a period-final syllable is determined without taking the beginning of the next period into account (cf. West 1982: 4), which makes a period-final syllable with a word-ending single consonant always heavy, while when it comes to a mid-period position, a short vowel needs to be followed by at least two consequent consonants to be scanned as a heavy syllable.

Considering all that, it is simply more probable for heavy syllables to occur in the period-final position more often than at the beginning and in the middle. In addition, because of the peculiarities of Greek script, it is also much more likely to identify heavy syllables in especially fragmentary passages in which the semantics become incredibly vague and also grammar and morphology become unanalysable. Therefore, the results are naturally biased towards heavy syllables.

The samples were quite small due to the fragmentary nature of the material. Therefore, one cannot derive general metrical laws from the results. Instead, metrical tendencies can be presented and indicated.

\section{Results and Discussion}

Chart 3 depicts the occurrence of heavy syllables in Sappho's Sapphic hendecasyllables.

The position of anceps was filled with a heavy syllable in $68.24 \%$ and with a light syllable in $31.76 \%$ of the occurrences. In brevis in longo, the occurrence of a heavy syllable was $80.79 \%$, and for light syllables, it was $19.21 \%$. Therefore, heavy syllables tend to be clearly favoured in these positions.

Chart 4 depicts the occurrence of heavy syllables according to additional analysis of Sappho's hendecasyllables with dubious positions added.

With the dubia added, Sappho's hendecasyllabic anceps and brevis in longo positions exhibited a slightly greater preference for heavy syllables. The anceps was heavy in $69.1 \%$ and light in $30.9 \%$ of the cases, while the occurrence of brevis in longo was $81.17 \%$ heavy and $18.83 \%$ light.

To illustrate, fragment 16 begins with a line in which there are heavy syllables in both free positions, and this could be called a more typical variety.

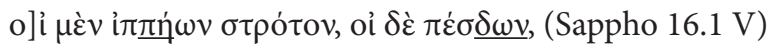

Later in the poem, there are lines with both a heavy and light syllable. Lines 17 and 19 have a heavy syllable in the first free position; line 18 has a heavy syllable at the end. 


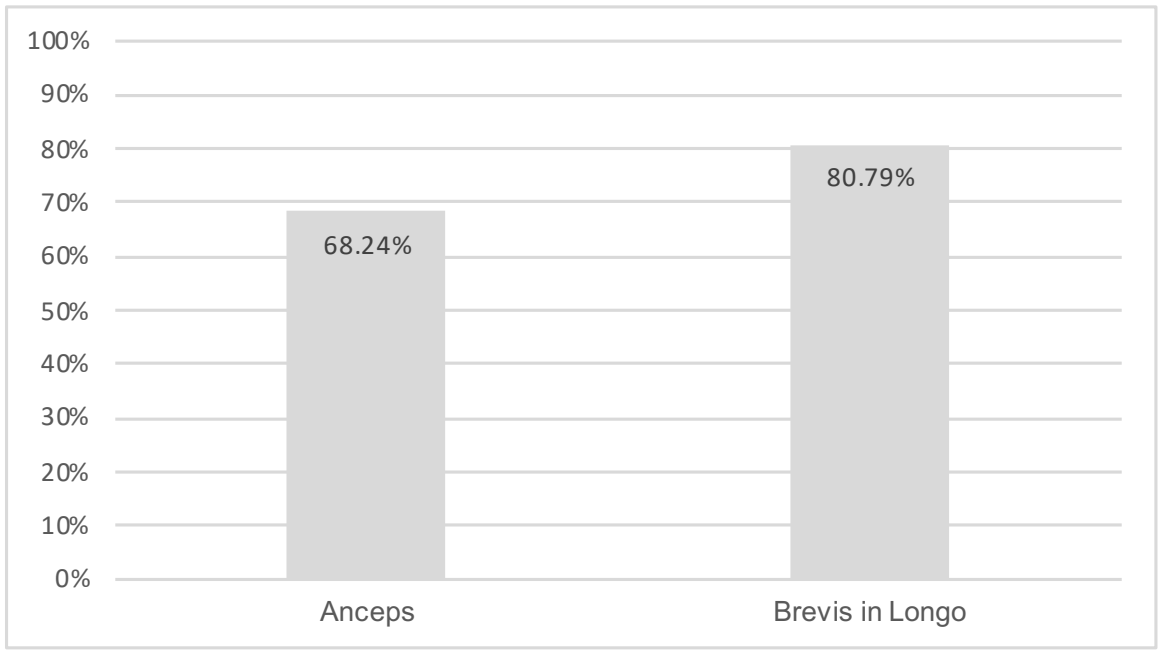

Chart 3. The occurrence of heavy syllables in Sappho's Sapphic hendecasyllables in the positions of anceps and brevis in longo.

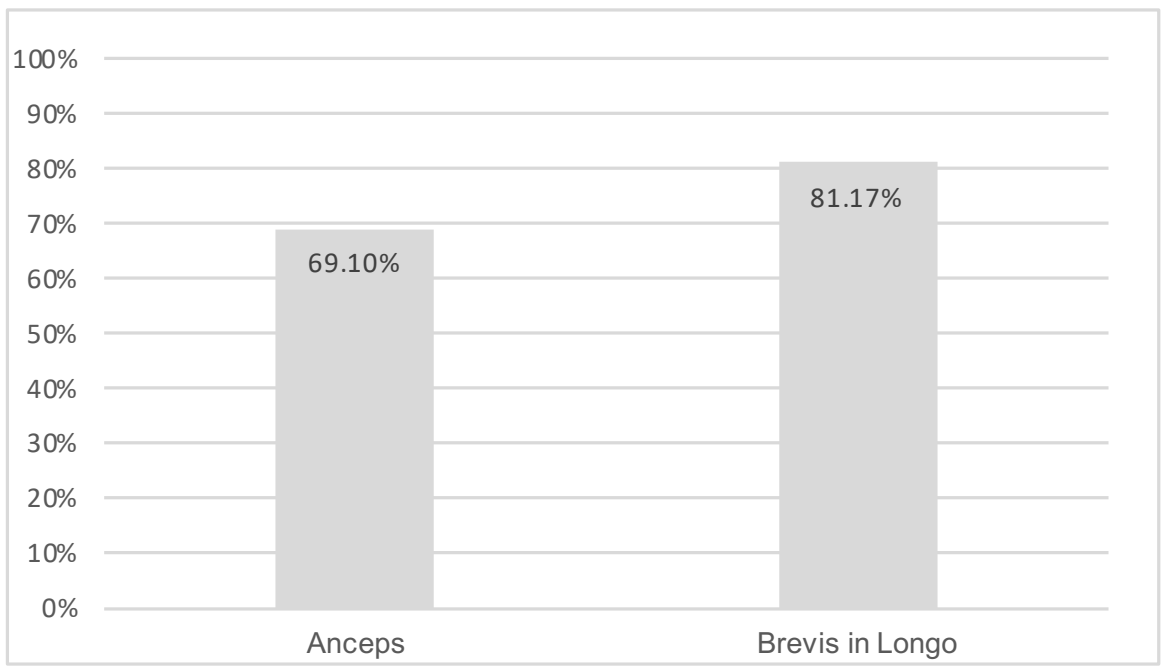

Chart 4. The occurrence of heavy syllables in Sappho's Sapphic hendecasyllables in the positions of anceps and brevis in longo with dubious lines included. 


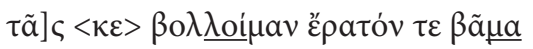

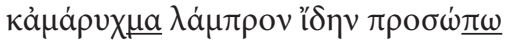

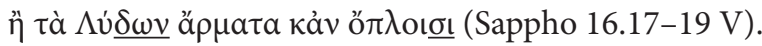

Nevertheless, in the same poem, a line of the least typical variety has been constructed.

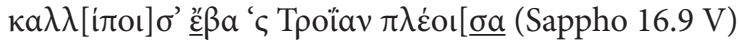

Chart 5 demonstrates the quantitative preferences of Alcaeus in the free positions of his Sapphic hendecasyllables that could be analysed with certainty.

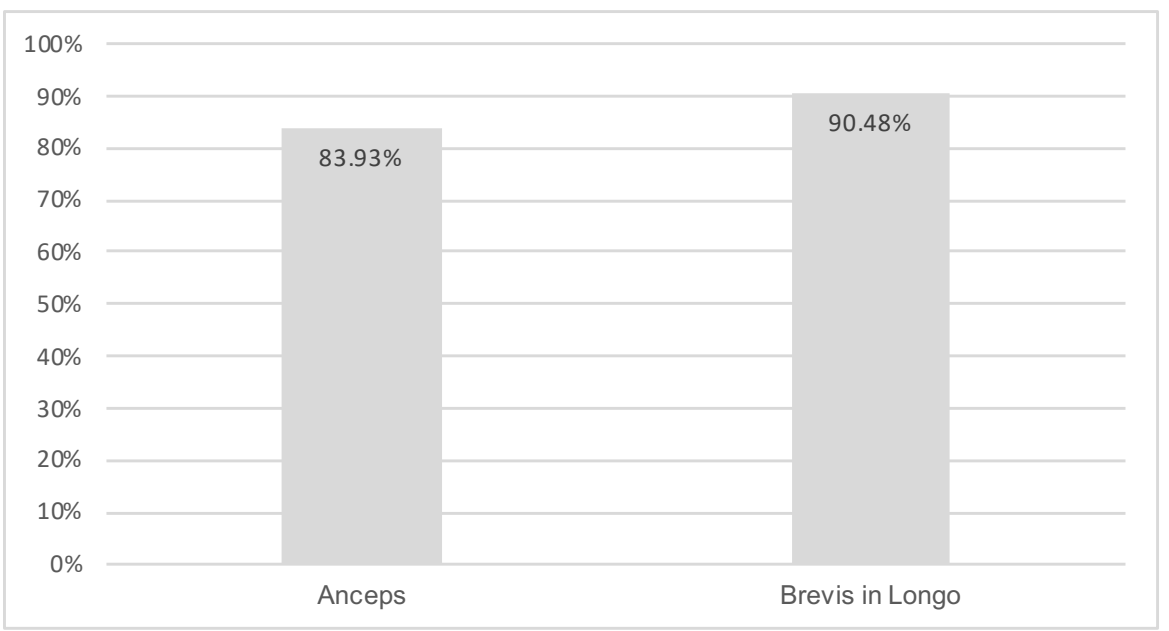

Chart 5. The occurrence of heavy syllables in Alcaeus's Sapphic hendecasyllables in the positions of anceps and brevis in longo.

Alcaeus's quantitative preferences are even more biased towards heavy syllables than Sappho's. The occurrence of heavy syllables was $83.93 \%$ and $90.48 \%$ in the position of anceps and brevis in longo respectively, leaving $16.07 \%$ and 9.52\% for light syllables.

Chart 6 shows the occurrence of heavy syllables in Alcaeus's Sapphic hendecasyllables when dubious data was added. 


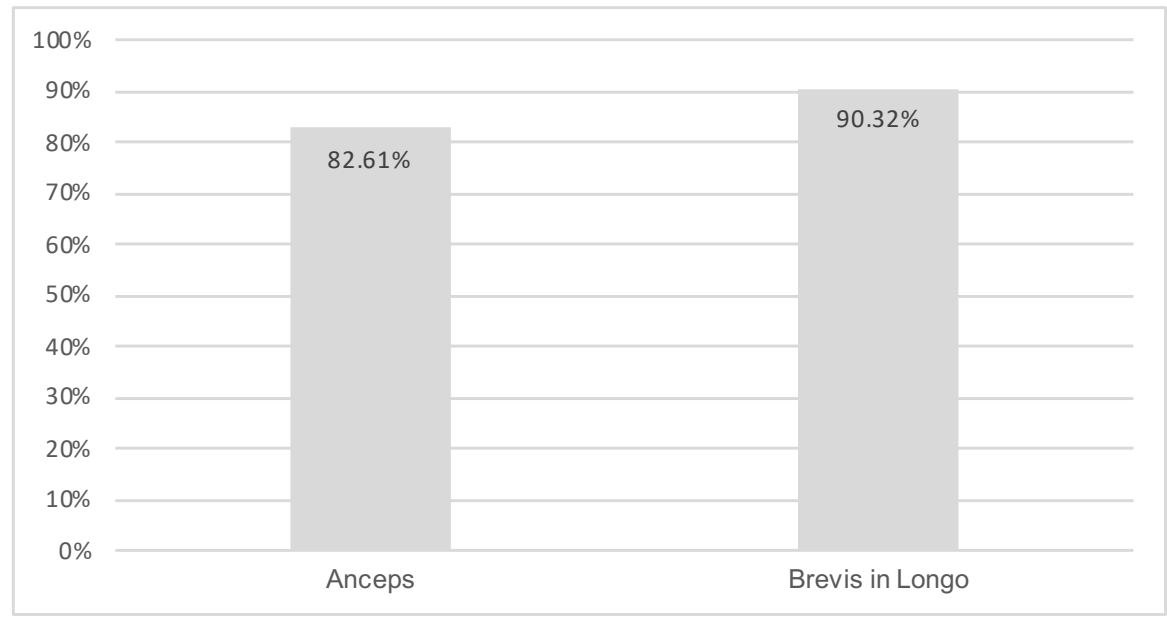

Chart 6. The occurrence of heavy syllables in Alcaeus's Sapphic hendecasyllables in the positions of anceps and brevis in longo with dubious lines included.

The analysable dubious data lowered the prevalence of heavy syllables in Alcaeus's hendecasyllabic anceps and brevis in longo positions. However, the difference is so slight that his more pronounced preference for heavy syllables - compared to Sappho - remains virtually without change. Anceps positions were filled with a heavy syllable in $82.61 \%$ and with a light syllable in $17.39 \%$ of the cases. Brevis in longo had a heavy syllable in $90.32 \%$ of the occurrences and a light one in $9.68 \%$.

Nevertheless, it should be kept in mind that the modern Alcaic corpus has fewer than 10 well-preserved strophes of Sapphic stanza, while a noticeably wider and more analysable selection of poetry in the meter has been preserved from Sappho.

Ancient scholars have expressed conflicting opinions on who the original user or creator of the Sapphic stanza was, and both Alcaeus and Sappho have been named (vd. Hephaestion Enchiridion de Metris 14.1; Marius Victorinus Ars Grammatica in Grammatici Latini 6.161).

Here we see two more typical lines with only heavy-syllabled free positions, followed by a less typical one where only the first position is heavy:

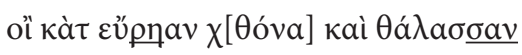

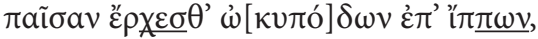

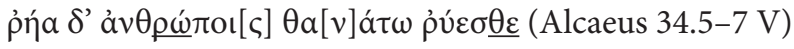


Fragment 361, next to which Voigt places the word fortasse [strophe Sapphica], consists of the following rare line of free positions filled with a light syllable:

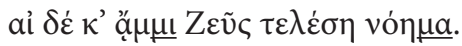

Chart 7 illustrates the occurrence of heavy syllables in the anceps and brevis in longo positions in Sappho's poetry that are definitely in aiolikon. The samples of aiolikon were the smallest. As pointed out above, only 3\% (or $8 \%$ with dubious lines) of the 1384-line Sapphic corpus are in this meter.

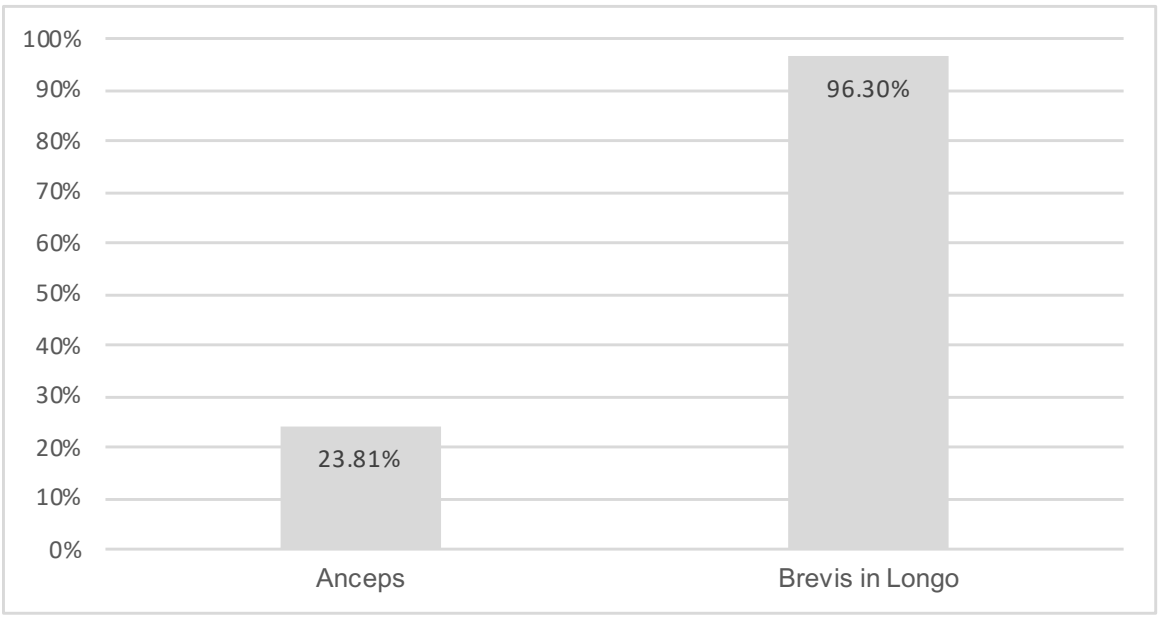

Chart 7. The occurrence of heavy syllables in Sappho's aiolikon in the positions of anceps and brevis in longo.

The analysis of well-preserved aiolikon showed that, in just $23.81 \%$ of the cases, the anceps was occupied by a heavy syllable. As light syllables occurred $76.19 \%$ of the times, light syllables are noticeably preferred. In the position of brevis in longo, the occurrence of heavy syllables was $96.3 \%$ and $3.7 \%$ for light syllables. Thus, in this position, there is a clear and vivid preference for heavy syllables, and the contrast between the beginning and the end of a verse could have been striking.

Chart 8 depicts Sappho's quantitative preferences in free positions, with the verses that might be in aiolikon added. 


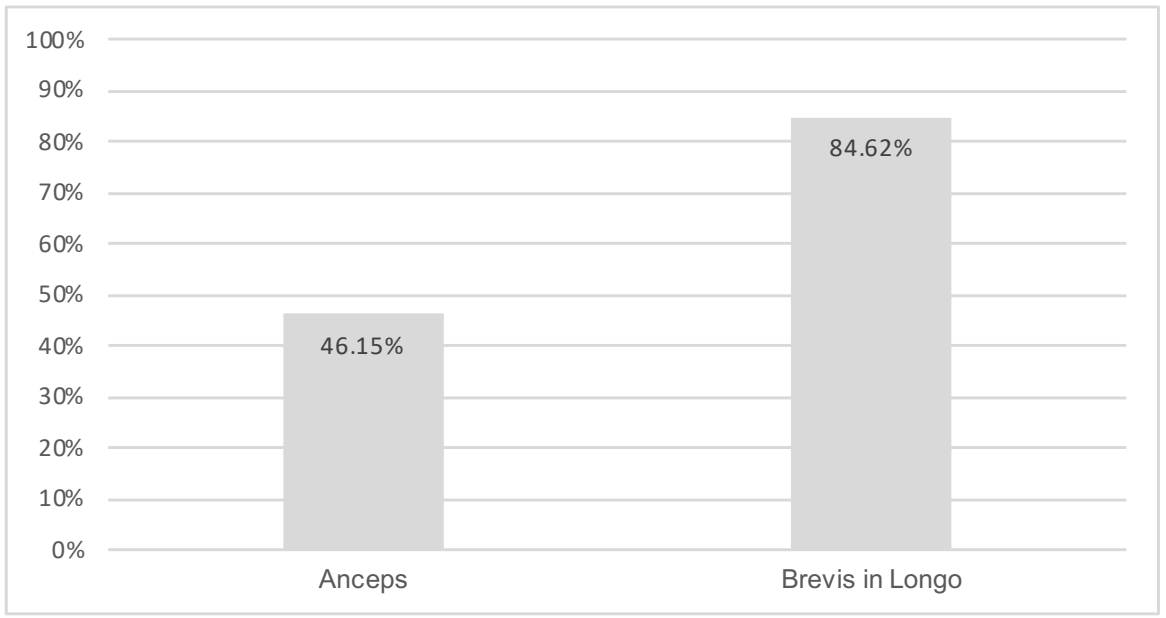

Chart 8. The occurrence of heavy syllables Sappho's poetry in the positions of anceps and brevis in longo with the lines possibly in aiolikon included.

Adding dubia raised the occurrence of heavy syllables in the position of anceps significantly, but the position still exhibits a clear preference for light syllables, which occurred in $53.85 \%$ of the cases, leaving $46.15 \%$ to the occurrence of heavy syllables. In the position of brevis in longo, however, heavy syllables are still favoured, with a rate of occurrence of $84.62 \%$, leaving $15.38 \%$ to light syllables.

Compared to the Sapphic hendecasyllable of both Aeolic authors, the aiolikon tends to display a significantly greater number of light syllables in the position of anceps. When it comes to brevis in longo, the data is more similar to Alcaeus's hendecasyllable in the final position if only positions that are definitely in the meter are taken into account, but they are more similar to Sappho's hendecasyllabic brevis in longo if we also consider dubia.

Nevertheless, a dyad of typical aiolika would look as follows. The first syllable of both lines is light, while the last one is heavy.

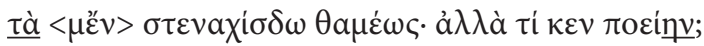

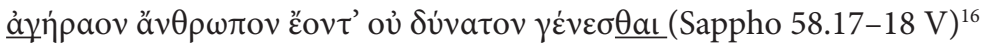

Fully atypical lines have not reached us.

16 All the lines from fragment $58 \mathrm{~V}$ are quoted accoring to Obbink (2009: 14). 
Here we have its preceding dyad with only light syllables:

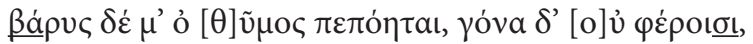

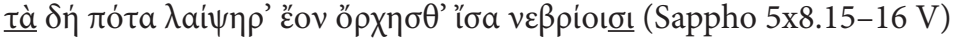

Despite this, most free positions from 4 fully preserved lines of fragment 81 are heavy, with only the anceps of 81.4 being light.

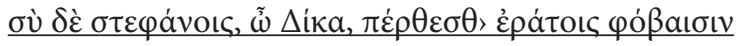

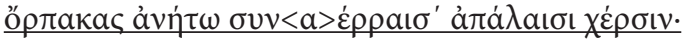

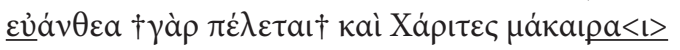

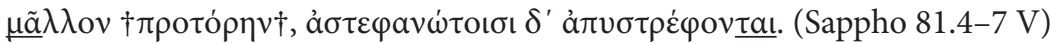

Based on these data, we can specify the metrical model of both meters using the generative approach. In the following schemes, $S$ signifies the strong positions, W weak positions, $\mathrm{X}$ anceps positions, and \& signs are metrical delimitators. The schemes cover only the tendencies of non-dubia.

A. Sappho’s Sapphic hendecasyllable

\section{\&SWSX $\mathrm{SWWSWSX}_{2} \&$}

The scheme is realized with the following rules:

1) $S$ is filled with one heavy syllable.

2) $W$ is filled with one light syllable.

3) $X_{1}$ is filled with one heavy syllable $68 \%$ of the time and the rest of the time with one light syllable.

4) $X_{2}$ is filled with one heavy syllable $81 \%$ of the time and the rest of the time with one light syllable.

B. Alcaeus's Sapphic hendecasyllable

\&SWSX $\mathrm{SWWSWSX}_{2} \&$

1) $S$ is filled with one heavy syllable.

2) $\mathrm{W}$ is filled with one light syllable.

3) $X_{1}$ is filled with one heavy syllable $84 \%$ of the time and the rest of the time with one light syllable.

4) $X_{2}$ is filled with one heavy syllable $90 \%$ of the time and the rest of the time with one light syllable. 
C. aiolikon

\& $\mathrm{X}_{1}$ SWWSSWWSSWWSWSX $_{2} \&$

1) $S$ is filled with one heavy syllable.

2) $W$ is filled with one light syllable.

3) $X_{1}$ is filled with one heavy syllable $24 \%$ of the time and the rest of the time with one light syllable.

4) $\mathrm{X}_{2}$ is filled with one heavy syllable $96 \%$ of the time and the rest of the time with one light syllable.

\section{Conclusion}

All in all, the comparative-statistical analysis showed that Sappho's Sapphic hendecasyllables exhibit a smaller percentage of heavy syllables in the quantity-free positions of anceps or brevis in longo than Alcaeus's hendecasyllables. Nevertheless, in the preserved and analysable poetry of both authors, heavy syllables prevailed in these positions even when dubious occurrences were added. For Sappho, $68.24 \%$ of anceps and $80.79 \%$ brevis in longo positions were heavy; with dubia included, the percentages were slightly larger: $69.10 \%$ and $81.17 \%$, respectively. In Alcaeus's case, the positions in question were $83.93 \%$ and $90.48 \%$ heavy; with dubia included: $82.61 \%$ and $90.32 \%$. In Sappho's aiolikon, on the other hand, the occurrence of light syllables was very apparent in the position of anceps (23.81\% of heavy syllables, but $46.15 \%$ with dubia included). In brevis in longo, the heavy syllables still prevailed (96.30\%; with dubia included, $84.62 \%$ ).

The fact that the so-called third lines of the Sapphic stanza were included in the analysis makes the data comparable with the use of the Sapphic hendecasyllable by subsequent creators, allowing us to see if and where these tendencies have prevailed or how they have changed. For further research, the tendencies of the later aiolikon could also be studied from this perspective. In addition, the positions of anceps and brevis in longo of the meters in question could be compared with their counterparts in other Greek verse forms, even author by author. ${ }^{17}$

17 This research was supported by Estonian Research Council grant no. PUT1231.

The author wishes to thank the anonymous reviewers for all the feedback and suggestions. 


\section{References}

Ahrens, Heinrich Ludolf 1868. De Theocriti carmine aeolico tertio nuper invento. Hannover: Typis Culemannianis.

Ahrens, Heinrich Ludolf 1868. Das alkmanische partheneion des papyrus. In: Philologus 27(2), 241-285. https://doi.org/10.1515/phil-1868-0202

Barris, Joan Silva 2011. Metre and Rhythm in Greek Verse (Wiener Studien. Beiheft 35) Wien: Verlag der Österreichischen Akademie der Wissenschaften.

Boedeker, Deborah 2009. No Way Out?: Aging in the New (and Old) Sappho. In: Greene, Ellen; Skinner Marilyn B. (eds.), The New Sappho on Old Age. Washington: Harvard University Press, 71-83.

Burris, Simon; Fish, Jeffrey; Obbink, Dirk 2014. New Fragments of Book 1 of Sappho. In: Zeitschrift für Papyrologie und Epigraphik 189, 1-28.

Crusius, Otto 1888. Stesichorus und die Epodische Composition in der Griechischen Lyrik. In: Commentationes Ribbeckianae, Leipzig: B. G. Teubneri, 1-22.

Dominicy, Mark 1994. Une grammaire des côla éoliens. In: Projet ARC "Typologie Textuelle et Théorie de la Signification", Rapport de recherches $n^{\circ} 2$. https://difusion. ulb.ac.be/vufind/Record/ULB-DIPOT:oai:dipot.ulb.ac.be:2013/130851/Holdings (accessed December 13, 2019).

Ferrari, Franco 2010. Sappho's Gift: The Poet and Her Community. Ann Arbor: Michigan Classical Press.

Golston, Chris; Riad, Tomas 2005. The Phonology of Greek Lyric Meter. In: Journal of Linguistics 41(1), 77-115. https://doi.org/10.1017/S0022226704003068

Hermann, Gottfried 1816. Elementa doctrinae metricae. Leipzig: Fleischer.

Korzeniewski, Dietmar 1968. Griechische Metrik. Darmstadt: Wissenschaftliche Buchgesellschaft.

Liberman, Gauthier 2007. Lédition alexandrine de Sappho. In: Bastianini, Guido; Casanova, Angelo (eds.), Studi e Testi di Papirologia 9, 41-65.

Lidov, Joel 2009. The Meter and Metrical Style of the New Poem. In: Greene, Ellen; Skinner Marilyn B. (eds.), The New Sappho on Old Age. Washington: Harvard University Press, 103-117.

Maas, Paul 1962. Greek Metre. Oxford: Clarendon Press.

Meillet, Antoine 1923. Les origines indo-européennes des mètres grecs. Paris: Les Presses Universitaires de France. 
Obbink, Dirk 2009. Sappho Fragments 58-59: Text, Apparatus Criticus, and Translation. In: Greene, Ellen; Skinner Marilyn B. (eds.), The New Sappho on Old Age. Washington: Harvard University Press, 7-16.

Obbink, Dirk 2014. Two New Poems by Sappho. In: Zeitschrift für Papyrologie und Epigraphik 189, 32-49.

Page, Denys 1955. Sappho and Alcaeus: An Introduction to the Study of Ancient Lesbian Poetry. Oxford: Clarendon Press.

Smyth, Herbert Weir 1920. A Greek Grammar for Colleges. New York [etc.]: American Book Company.

Voigt, Eva-Maria (ed.) 1971. Sappho et Alcaeus. Fragmenta. Amsterdam: Polak \& van Gennep.

West, Martin Litchfield 1982. Greek Metre. Oxford: Clarendon Press.

West, Martin Litchfield 1987. Introduction to Greek Metre. Oxford: Clarendon Press. 